\title{
Discussion: Climatic influence on geotechnical infrastructure: a review
}

Philip J. Vardon MEng, PhD

Assistant Professor, Section of Geo-Engineering, Delft University of Technology, Delft, Netherlands

Rashid Bashir PhD, PEng

Associate Professor, Department of Civil Engineering, York University, Toronto, Canada
Jitendra Sharma PhD, PEng

Professor and Chair, Department of Civil Engineering, York University, Toronto, Canada

\section{Contribution by R. Bashir and J. Sharma}

The contributors read the paper by Vardon (2014) with great interest and wish to commend the author for addressing the issue of incorporating climate change in geotechnical design, which is rapidly gaining importance in engineering practice. Although the paper provides an excellent review of the possible effects of climate change on geotechnical infrastructure, the contributors feel that there are other aspects of climate change that deserve further discussion, including a number of recent publications on the effect of climate change on expansive soils. The contributors also feel that a discussion on climate change effects on geotechnical infrastructure will not be complete without discussing soil covers, which are integral to landfills and mining waste management systems. As such, this discussion should be treated more as being complementary to the paper and less as a critique.

The author has proposed the use of the Penman-Monteith equation (Monteith, 1965) as the most common way of describing the evapotranspiration (ET) at the soil-atmosphere boundary. It is worth noting that this method provides estimates of potential evaporation (PE) or potential ET (PET) from a water body or a saturated ground. It is more realistic to consider actual evaporation (AE) or actual ET (AET) by accounting for the state of stress in the ground, which affects the actual rate of evaporation considerably (Fredlund et al., 2012). Water balance at the ground surface and associated moisture dynamics in the unsaturated zone cannot be quantified without an accurate estimation of AE. Coupled moisture-thermal flow models can be used for the estimation of $\mathrm{AE}$ at the ground surface (Wilson et al., 1994, 1997). Such models are also known as soil-atmosphere models (Fredlund et al., 2012). Different forms of coupled and uncoupled soil-atmosphere models have been summarised by Fredlund et al. (2011).

It is also worth noting that in most instances, it is the net effect of the change in precipitation and evaporation that influences the behaviour of geotechnical infrastructure. This net effect can be quantified using the concept of moisture index, such as the Thornthwaite moisture index (TMI) (Thornthwaite, 1948). The TMI is part of a water balance model for climate classification and can be used as an indicator of the supply of water in an area relative to the demand under historical, prevailing and future climatic conditions. In the past 60 years, the use of the TMI has spread in agriculture, forestry and urban infrastructure (Leao, 2014a), and it is now widely recognised as an indicator of climate change (Leao and Osman-Schlegel, 2013; McCabe and Wolock, 1992; McCabe et al., 1990; Philp and Taylor, 2012).

More recently, a number of researchers have related the TMI to climate change and its effect on geotechnical infrastructure, especially expansive soil movements (Harrison et al., 2012; Leao, 2014b; Leao and Osman-Schlegel, 2013; Mitchell, 2013; Philp and Taylor, 2012). Harrison et al. (2012) carried out analysis and modelling to investigate the relationship between climate change and shrinkage and swelling behaviour of expansive soils in South East England, concluding that there will be a general rise in susceptibility to shrinkage and swelling. One of the shortcomings of their research is the use of precipitation and temperature data as proxies instead of moisture deficit information. Mitchell (2013) quantified the climate change effects on expansive soil movements for the Australian cities of Adelaide, Melbourne, Sydney and Perth for the years 2030 and 2070 and concluded that a continuing revision of the footing standard is required to take into account the climate change. Leao (2014b) used GIS (geographic information system) to produce a map of potential risk for housing damage from expansive soil ground movement due to climate change for Victoria, Australia, in which attributes of the TMI and population change were combined. This study concluded that medium- and high-potential risk accounts for a little more than $11 \%$ of the total area of Victoria, most of it in the urbanised portion including metropolitan Melbourne and the surrounding region.

Soil covers or caps are an important class of geotechnical infrastructure that will be severely affected by climate change. Figure 3, taken from Global Acid Rock Drainage Guide (INAP, 2009), is used in many instances for identifying the type of cover that will be required for a tailings management facility. It can be seen from Figure 3 that at the preliminary design level, the most important factors to be considered are precipitation and PE. Climate classification and soil-atmosphere modelling with multi-year climatic datasets are important parts of the soil cover design process (Fredlund et al., 2012). Although climate is a primary variable in the design of soil covers, documented examples of effect of climate change on soil covers are rare. A report on the 


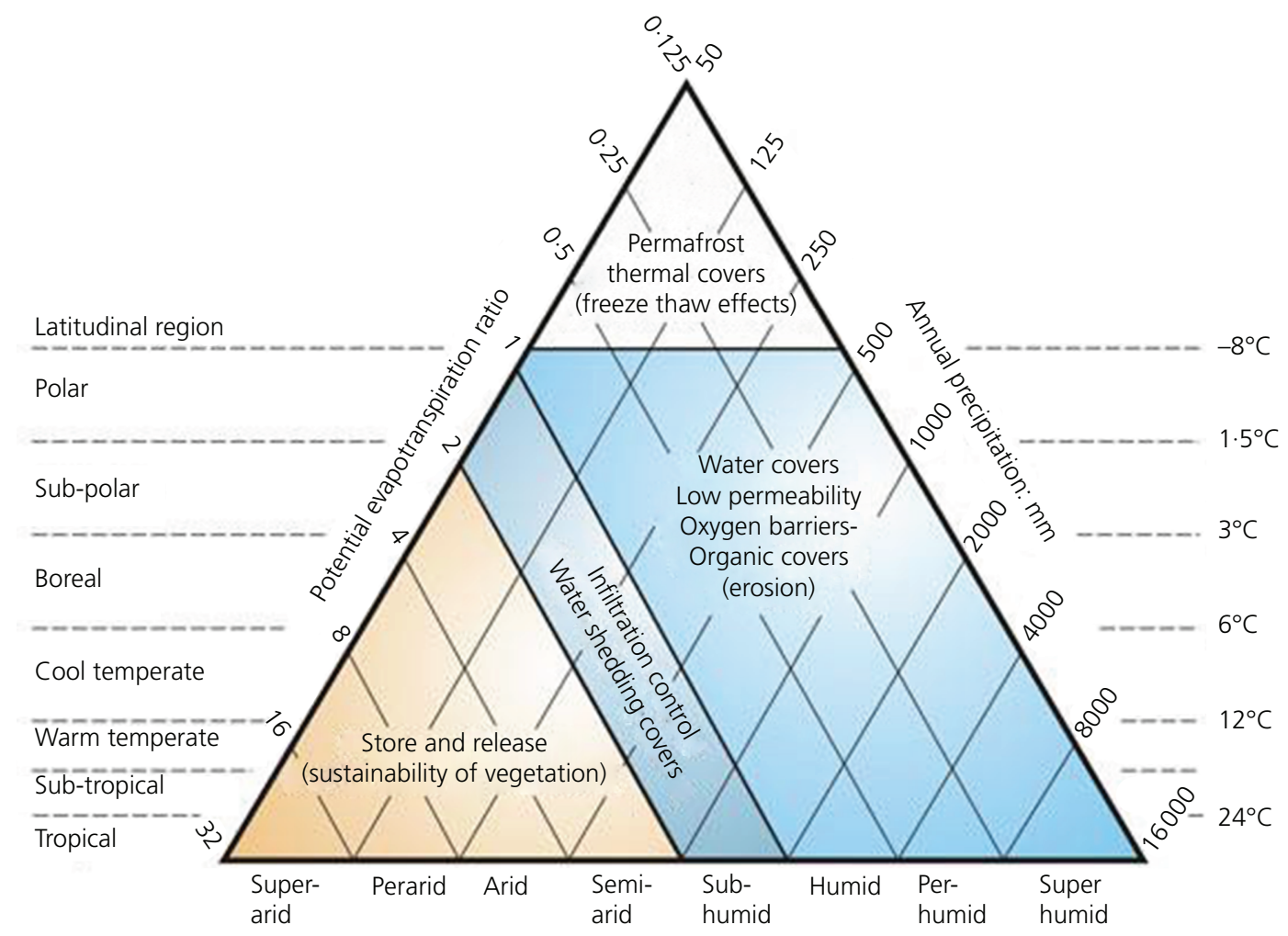

Figure 3. Cover systems and climate types (INAP, 2009)

effect of climate change on acid rock drainage sponsored by the Mining Association of Canada (MEND, 2011) addresses various issues related to climate change and its effect on acid rock drainage including soil covers placed over the reactive tailings. It points out that most types of covers will be vulnerable to climate change to varying degrees. The two types of covers that are more prone to climate change are the store-and-release covers and the covers that rely on permafrost for waste containment. Increased precipitation quantities and changes in precipitation intensity can overwhelm the design storage capacity of the store-and-release covers resulting in increased percolation to the underlying waste. Similarly, decrease in precipitation and increase in PE and extended periods of drought can lead to reduced moisture storage in the cover leading to increased oxygen influx to the acid-generating tailings. Covers that rely on development of permafrost for waste containment are likely to fail as a result of rising temperatures and deteriorating permafrost conditions.

\section{Author's reply}

The discussion by Bashir and Sharma provides an interesting further commentary on the subject of climatic influence on geotechnical infrastructure and identifies and extends specific contexts where the features discussed in the paper are applicable. As identified by the authors of the discussion, this subject is growing in importance in engineering practice, and further details add to the debate of how to best incorporate these impacts into engineering practice. This discussion and further work on the impacts of climate change on geotechnical infrastructure are important to further appreciation and knowledge of the potential and likely long-term effects, and therefore to prevent unnecessary damage, financial costs and potential injury or deaths.

The approaches of calculating the actual evapotranspiration (AET) from soil, such as the Penman-Monteith equation (Monteith, 1965), were discussed. As was noted, this approach provides a maximum, or potential evapotranspiration, as was identified in the original paper. The flux through the soil represents an important condition to calculate the AET, as discussed by Fredlund et al. (2012), and is well recognised by the paper author, for example, in examining the atmospheric drying of mine tailings (Vardon et al., 2014). The current interest in soil-atmosphere interaction, which provides a critical boundary condition for the interaction of climate and geotechnical infrastructure, is welcomed, and current research on various aspects demonstrates that this topic is timely and worthy of further investigation. For example, research in this area was presented at a mini-symposium, co-convened by the author, at the International Association for Computer Methods and Recent Advances in Geomechanics (IACMAG) conference in September 2014, which included topics such as thermal and water fluxes between the soil and atmosphere, unsaturated flow including surface permeability and desiccation cracking (e.g. Cleall et al., 2014; Harnas et al., 2014; Sánchez et al., 2014; Song et al., 2014; Toll et al., 2014; and others). 
The net effect of changes in precipitation and evaporation, quantified by the Thornwaite moisture index (TMI), was discussed as the major influence on the behaviour of geotechnical infrastructure. It is agreed that, overall, this may be used as an indicator of the supply of water and can be used as an indicator of climate change. However, in terms of macro stability issues, and environmental barriers, the use of the TMI alone cannot be justified, as the dynamics of drying and wetting can be important (e.g. van Esch, 2012). Therefore, as outlined in the original paper, it is important to recognise both the changes to the mean precipitation and evaporation and the intensity. The discussion regarding swelling soils and the interaction with foundations illustrates the wide breadth of potential climatic effects and indeed provides an interesting question of what can be considered geotechnical infrastructure. In the original paper, it was considered that geotechnical infrastructure was formed from geotechnical materials, rather than in this case geotechnical material hosting (and interacting with) structural infrastructure.

An overview of the potential impact of climatic change on soil covers is presented as part of the discussion; soil covers are an important geotechnical infrastructure that is likely to be affected by climatic change. This discussion adds to the range of engineering areas that need to be considered. Moreover, to have sustainable design practices, climate effects should be considered at the design stage. Permafrost regions were not the focus of the original paper, as these areas already have received substantial attention, but as the authors of the discussion point out, covers that rely on permafrost will be vulnerable to climate change.

\section{REFERENCES}

Cleall PJ, Muñoz-Criollo JJ and Rees SW (2014) Assessment and representation of thermal surface fluxes in soils. Proceedings of 14th International Conference of the International Association for Computer Methods and Recent Advances in Geomechanics, Kyoto, Japan, pp. 1321-1326.

Fredlund DG, Rahardjo H and Fredlund MD (2012) Unsaturated Soil Mechanics in Engineering Practice. Wiley, Hoboken, NJ, USA.

Fredlund MD, Zhang JM, Tran D and Fredlund DG (2011) Coupling heat and moisture flow for the computation of actual evaporation. Proceedings of the Pan-American Canadian Geotechnical Society Conference, Toronto, Canada.

Harnas FR, Rahardjo H, Leong EC and Wang JY (2014) Effect of evaporation on the performance of capillary barriers with recycled asphalt material. Proceedings of 14th International Conference of the International Association for Computer Methods and Recent Advances in Geomechanics, Kyoto, Japan, pp. 1309-1314.

Harrison AM, Plim JFM, Harrison M, Jones LD and Culshaw MG (2012) The relationship between shrink-swell occurrence and climate in south-east England. Proceedings of the Geologists' Association 123(4): 556-575.

INAP (2009) Global Acid Rock Drainage Guide (GARD Guide). http://www.gardguide.com/ (accessed 21 November 2014).
Leao S (2014a) Impact of climate change in Victoria, Australia: mapping 100 years of Thornthwaite moisture index. Geographical Research 52(3): 309-327.

Leao S (2014b) Mapping potential risk for housing damage from ground movement due to climate change. International Journal of Environmental Science and Development 5(4): 387-392.

Leao S and Osman-Schlegel NY (2013) TMI for urban resilience: measuring and mapping long-term climate change effects on soil moisture. Proceedings of the 7 th Australasian Housing Researchers' Conference: Housing the Needs of Diverse Populations. http://business.curtin.edu.au/ local/docs/ahrc13/TMI-for-urban-resilience.pdf (accessed 21 November 2014).

McCabe GJ and Wolock DM (1992) Effects of climatic change and climatic variability on the Thornthwaite moisture index in the Delaware River basin. Climatic Change 20(2): 143-153.

McCabe GJ, Wolock DM, Hay LE and Ayers MA (1990) Effects of climatic change on the Thornthwaite moisture index. Water Resources Bulletin 26(4): 633-643.

MEND (Mine Environment Neutral Drainage) (2011) Climate change and acid rock drainage - risks for the Canadian mining sector, Report 1.61.7.

Mitchell PW (2013) Climate change effects on expansive soil movements. Proceedings of the 18th International Conference on Soil Mechanics and Geotechnical Engineering, Paris.

Monteith JL (1965) Evaporation and environment. Symposium on the Sociological Experimental Biology 19: 205-224.

Philp M and Taylor M (2012) Beyond agriculture: exploring the application of the Thornthwaite Moisture Index to infrastructure and possibilities for climate change adaptation. ACCARNSI Discussion Paper X.

Sánchez M, Manzoli O and Guimarães L (2014) Modeling drying cracks in soils using a mesh fragmentation method. Proceedings of 14th International Conference of the International Association for Computer Methods and Recent Advances in Geomechanics, Kyoto, Japan, pp. 1353-1358.

Song WK, Cui YJ, Tang AM and Ding WQ (2014) Water evaporation experiments in environmental chamber. Proceedings of 14th International Conference of the International Association for Computer Methods and Recent Advances in Geomechanics, Kyoto, Japan, pp. 1359-1364.

Thornthwaite CW (1948) An approach toward a rational classification of climate. Geographical Review 38(1): 55-94.

Toll DG, Rahim MSMd, Karthikeyan M and Tsaparas I (2014) Soil atmosphere interactions for analysing slopes in tropical soils. Proceedings of 14th International Conference of the International Association for Computer Methods and Recent Advances in Geomechanics, Kyoto, Japan, pp. 1333-1338.

van Esch JM (2012) Modeling groundwater flow through embankments for climate change impact assessment. Proceedings of the XIX International Conference on Water Resources, CMWR 2012, IL, USA. 
Vardon PJ (2014) Climatic influence on geotechnical infrastructure: a review. Environmental Geotechnics, http://dx.doi.org/10.1680/envgeo.13.00055.

Vardon PJ, Nijssen T, Yao Y and van Tol AF (2014) Numerical simulation of fine oil sand tailings drying in test cells.

Proceedings of the Fourth International Oil Sands Tailing Conference (IOSTC'14), Canada, pp. 59-69.
Wilson GW, Fredlund DG and Barbour SL (1994) Coupled soil-atmosphere modeling for soil evaporation. Canadian Geotechnical Journal 31(1): 151-161.

Wilson GW, Fredlund DG and Barbour SL (1997) The effect of soil suction on evaporative fluxes from soil surfaces. Canadian Geotechnical Journal 34(1): 145-155. 